\title{
Research on the Financial Strategy of the Small and Medium-sized Enterprises in China
}

\author{
Haihua Gu, Bing Bai, Zhiqiong Guo \\ Business School, Jiangsu Normal University, Xuzhou Jiangsu, 221116, China \\ guhh1023@163.com,szzxbb@163.com,joan_monday@163.com
}

\begin{abstract}
Nowadays, more and more enterprises begin to take the financial management as one of the core management of an enterprise, especially the small and medium-sized enterprises in China. They play an increasing role in the process of economic development and reform. In the face of new market development prospects, the correct reasonable implementation of financial strategy will provide great support technology and the management idea for small and medium enterprises. This paper analyzes the characteristics of small and medium-sized enterprises and reveals its financial strategy problems, and put forward the reasonable measures by case study of Jiangsu Yunyi Electric Limited by Share Ltd.
\end{abstract}

Keywords-Medium-sized and small enterprises, Financial strategy, Financial management

\section{中小企业财务战略研究}

顾海华 白冰 郭志琼

江苏师范大学商学院, 徐州, 江苏, 中国

摘 要 当前,越来越多的企业开始以财务管理作为企业管理的核心, 逐步将财务战略管理提升至一个新的高度, 尤其是我国的中 小企业, 它们在经济发展的过程中起到了提高资金流动等一系列至关重要的作用。面对新的市场发展前景, 财务战略的正确合理实施, 将为中小企业提供技术力量以及经营理念各方面的巨大支持。本文分析了分析中小企业的特点及存在的相关财务战略问题，以江苏云 意电气股份有限公司为案例分析, 提出中小企业财务战略选择的合理措施。

关键词 中小企业, 财务战略, 财务管理

\section{1. 引言}

近些年, 中国的物价水平持续走高, 加之宏观经济的 不景气等一系列的影响因素, 造成国内经济发展水平受到 一定的冲击, 导致企业整体的投资环境质量逐步下降, 这 些问题的出现, 让很多企业出现了不同程度的财务发展困 境, 给企业今后的发展带来了困扰。中小企业经过漫长的 发展, 对 GDP 贡献已经高达 50\%, 对中国国民经济的增长 有着不容小觑的作用, 但随着外部环境的日趋紧张, 中小 企业要想在如今这种动态的环境下, 继续求得一席之地, 就应该充分认清企业目前所处的经济地位, 如何在这样一 个大环境中从客观的角度制定一个符合中小企业自身财务 状况的战略目标, 以提高财务目标为目的, 关系到企业的 优胜劣汰。由此可见, 结合实际情况正确实施企业财务战
略管理, 正在逐步成为中国大多数企业进行财务管理的首 要选择。

\section{2. 中小企业的界定}

中小企业在公司经营规模、人员数量、资产总额等方 面较之大型企业相对较少, 每个国家的划分标准不同, 现 行规定大致分为中型、小型、微型三类, 基本上可以分为 定量标准和定性标准。前者主要根据公司的员工总数、资 金总额、营业收入、市场占有率等作为划分标准, 后者则 以企业所有权集中制度、自主经营程度、管理方式以及在 行业内所处的地位作为划分标准。相比之下, 定量标准更 直观, 因此, 通常以定量标准作为主要的划分依据。由于 本文涉及的企业所处生产制造业，生产制造业属于工业类 别, 在此仅就这一划分标准进行讨论。

中国 2003 年发布了《中小企业标准暂行规定》, 本规 
定只划分了中型和小型企业, 适用的行业范围较为狭窄; 而 2009 年国务院又发布了新的《中小企业划型标准规定》, 相比较 2003 年的规定, 不但增加了微型企业的划分, 在适 用的行业范围上也更加广阔, 而且在包含传统行业的基础 上, 又适当的增加了一些新兴的行业。

表 1 中小企业划分标准比较 (工业行业) ${ }^{(1)}$

\begin{tabular}{|c|c|c|}
\hline & 2003 年 & 2009 年 \\
\hline \multirow[t]{2}{*}{ 划分依据 } & 员工总数、销售额、资产额 & 员工总数、营业收入 \\
\hline & $\begin{array}{c}<2000 \text { 人或 }<30000 \text { 万或 } \\
<40000 \text { 万 }\end{array}$ & $<1000$ 人或 < 40000 万 \\
\hline 中型企业 & $\begin{array}{c}\geq 300 \text { 人且 } \geq 3000 \text { 万且 } \\
\geq 4000 \text { 万 }\end{array}$ & $\geq 300$ 人且 $\geq 2000$ 万 \\
\hline 小型企业 & 其余为小型企业 & $\geq 20$ 人且 $\geq 300$ 万 \\
\hline 微型企业 & 无此标准 & $<20$ 人或 $<300$ 万 \\
\hline
\end{tabular}

从上表可以看出, 较 2003 年的划分标准, 2009 年实 行的新标准更加符合中国社会和经济发展的水平, 针对性 更加明显, 有利于中小企业上升到一个新的高度。

\section{3. 企业财务战略的基本内容和特点}

“战略”一词最早应用于军事方面, 是战术与谋略的完美 结合。随着时代的发展、科技的进步, 现代“战略”一词已 经不仅仅局限于军事领域, 它被广泛应用到了政治和经济 领域, 在社会生活中起到了重要的指导作用, 表现为更加 全面的对策和方法。

财务战略是企业根据内外部环境、自身发展能力, 用 战略的思想方式, 以实现企业长期财务管理目标为目的的 一种解决财务相关问题的战略方针。企业财务战略主要包 括投资、融资和分配三个方面, 投资战略是一种优化投资 方向的战略性筹划, 融资战略涉及证券等多种方式的融资, 分配战略则是全面对战略规划的方向做好显著地分配。

财务战略不但具有战略的共性, 而且具有财务的个性。 主要特征表现在以下几个方面: 首先, 全面性和长期性相 结合。制定企业的财务战略, 并不只是为了解决眼前的问 题, 而是为了企业今后长远发展而制定的, 并且是一种全 方位的优化配置安排, 对企业发展起到指导和引领的作用。 其次, 动态性和风险性相结合。企业的财务战略时刻跟随 经济环境而调整, 在谋求获利能力和营运能力的同时, 充 分肯定风险的存在并加以防范。最后, 全员性和特殊性相 结合。从纵向考虑, 财务战略的制定应当依照企业高层领

(1)《中小企业划型标准规定》（国发 [2009]36号）.
导、企业财务部经理、财务部基层员工为一体的管理过程, 横向考虑, 财务战略应当与其他战略相互配合, 相互制约, 因而达到企业资金的最优化使用。

\section{4. 中小企业财务战略管理的现状与问题分析}

\section{1 中小企业的发展现状}

第一, 中小企业的数量在不断增加, 发展主体不断扩 大。2011 年, 国务院发展研究中心通过调查得知, 中国的 中小企业占据企业总数量的九成之多, 中小企业的发展已 经达到了 5000 万家, 比 2006 年的 835 万家的确增长了很 多, 截止去年末, 徐州市就拥有 2650 家。

其次, 经济贡献不断增多, 支撑地位明显上升。就徐 州市的中小企业而言, 新增就业岗位贡献十分巨大, 达到 了 $80 \%$ 以上, 营业收入已经超过 5000 亿元, 税后利润较往 年同期增长 $37 \%$ 左右 (3)。

第三, 发展质量明显提升, 可持续发展不断增强。在 徐州, 普通的制造企业和其他传统企业, 正在加快步伐提 升品牌效益, 例如海伦哲等一批科技含量水平高、有一定 市场竞争能力的中小企业正在不断成长, 产品质量的不断 上升，基本覆盖了工业的 36 个大类行业。

\section{2 中小企业财务战略管理的问题分析}

总体来说, 大多数中小企业财务战略并不明确, 即使 有些企业制定了相应的财务战略, 而实质上则是形同虚设, 并没有充分发挥实质的作用。

1.部分企业决策较为简单, 财务发展过程中缺乏足够 的管理信息支持。

企业财务部是一个相对敏感的部门, 一些规模相对较 小、层次处于较低水平的企业, 财务人员一般由企业领导 者直接任免, 这些人员缺乏较强的财务分析能力和决策能 力, 尤其是一些私营的企业, 加之家族式的经营管理方式, 导致企业的管理权和经营权过于集中。而且, 中小企业的 财务机构层次划分不明确, 有些企业甚至只设置一个综合 财务部门, 没有明确专职的财务管理人员, 任职的相关人 员身兼数职, 既涉及会计核算, 又涉及现金管理, 导致中 小企业在财务战略管理的过程中会计信息表达不准确。

2. 部分企业融资相对困难, 资金周转率相对较低。

大多数中小企业实行融资战略, 目的是为了扩大公司 的经营规模, 多数企业选择银行贷款的目的也是为了规避 控股权的削弱。

由于中小企业多处于创业阶段, 经营时间过短, 抵抗 风险的能力明显小于大型企业。企业的上层领导关心的是 企业的生存发展问题, 便忽视了经营资料的整理和分析, 
不愿意参加任何资信评估, 甚至冒险从事民间借贷的行为。 这种情况, 使得银行等众多投资主体, 难以衡量其真实的 发展情况, 而做出拒绝资金申请投放的决定。银行为保证 资金的安全, 更愿意将有限的资金贷给大型企业。另外, 部分企业没有做好长期规划, 在未来的几年之内没有到股 票市场中小企业板块融资的计划, 说明对于发行股票融资 的方式并不看好。

3. 受国家宏观经济影响, 中小企业利润空间受到严重 挤压。

自 2011 年以来, 人民币对美元已累计升值 $1.97 \%$, 尽 管中国大多数的中小企业收到的订单的总量比往年提升了 许多, 但由于企业生产成本等一系列因素的变化, 企业从 中得到的营业利润却大大降低, 国家宏观经济环境的一系 列变化, 使传统产业的中小企业首当其冲受到冲击。面对 企业经济效益的下降，一些中小企业老板为了挽回损失， 把自身的企业作为融资的条件, 甚至不惜冒险挪用向银行 贷款的资金去投资房地产领域, 从事高风险的经营。如果 美元汇率持续走低、人民币进一步升值, 中国将会有大量 的中小企业面临关门歇业的窘境。

4. 中小企业社会化服务体系不完善, 需要进一步优化 加强。

中小企业受到规模、资金的影响, 很难依靠自身的条 件建立关于人员培训等方面的服务机构。相关研究表明, 中小企业的战略发展是一个长期的过程, 有关政府机构给 予相关帮助中小企业进步的财政政策并不够完善, 同时, 在教育培训、管理咨询、市场营销、技术开发和法律支援 等方面缺失一大批社会中介组织提供支持。目前, 政府部 门拨用建设性资金所建设的社会中介服务机构, 往往只对 本部门、本系统内的一些中小企业展开服务, 不仅服务范 围较小, 而且局限范围相对较大。另外, 中国一些城市也 发扬创新精神, 设立一些商业性较强的中介公司, 但由于 服务费用十分高昂, 并不有利于社会化服务的开展。

\section{5. 案例分析：云意电气公司财务战略分析}

\section{1 案例背景}

江苏云意电气股份有限公司依靠徐州特殊的地理位 置, 主要以中国的新车配套市场为基础, 通过企业自主管 理等一系列的经营模式, 从事车用整流器和调节器等汽车 零部件、电力电子元件的研发、生产和销售, 在中国属于 典型的汽车零件制造业产业。

\section{2 云意电气公司财务战略分析}

如何对一个企业实施准确的财务战略决策, 最重要的
是进行合理的财务战略分析, 一些主要财务因素的变动, 能够准确反映出企业资本结构等存在的部分问题。

\section{1. 财务比率分析}

表 2 云意电气公司的财务比率表 ${ }^{(2)}$

\begin{tabular}{|l|l|l|l|l|}
\hline 比率分类 & 比率名称 & 2010 年 & 2011 年 & 2012 年 \\
\hline 偿债能力 & 流动比率 & $2.93 \%$ & $2.75 \%$ & $8.27 \%$ \\
\hline & 速动比率 & $1.96 \%$ & $1.96 \%$ & $7.49 \%$ \\
\hline & 资产负债比率 & $27.61 \%$ & $25.98 \%$ & $11.58 \%$ \\
\hline 营运能力 & 应收账款周转率 & 4.37 次 & 4.75 次 & 4.25 次 \\
\hline & 总资产周转率 & $1.39 \%$ & $1.17 \%$ & $0.59 \%$ \\
\hline & 存货周转率 & & & 3.39 次 \\
\hline 盈利能力 & 净利润率 & $71.37 \%$ & $72.26 \%$ & $23.25 \%$ \\
\hline & 总资产报酬率 & $26.27 \%$ & $25.81 \%$ & $13.90 \%$ \\
\hline
\end{tabular}

根据云意电气公司 2010 年 2012 年财务比率的分析, 可以看出, 公司最近三年的流动比率和速动比率都有所增 加, 特别是在 2012 年增长十分迅速, 说明企业 2012 年 3 月的上市起到了推波助澜的作用, 但是企业的资产负债比 率则呈下降趋势, 就整体而言, 体现企业的偿债能力正在 逐步提高。2012 年, 公司应收账款周转率下降和总资产周 转率都有所下降, 二者作为衡量企业资产状况的重要指标, 下降即表示企业回收应收账款的效率和运用资产从事经营 的效率也相应减弱, 会使得企业的营运资金周转方面出现 一定的问题, 导致资产利用率下降。最后, 该公司的盈利 指标都呈下降的趋势。这充分说明公司的偿债能力虽然提 高, 但资产周转的速度并没有改善, 盈利能力有下降的趋 势。所以, 应该加强企业的产品销售能力, 严格控制制造 成本费用, 以扭转局势。

公司资产负债表部分信息比较1

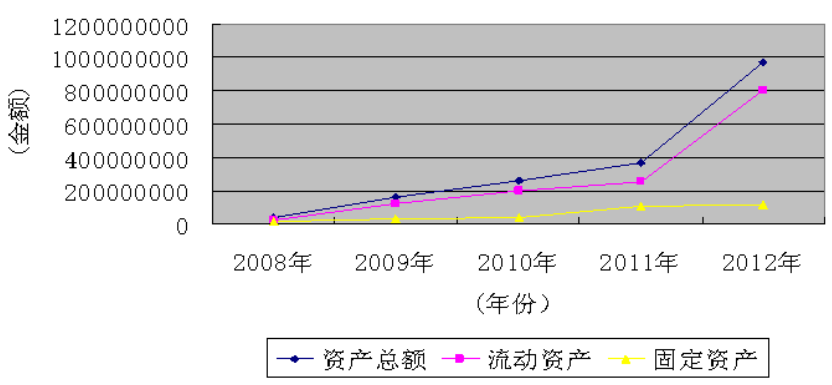

图 1 云意电气公司资产比较情况

\footnotetext{
数据来源于巨潮资讯网.
} 
公司资产伎债表部分信息比较2

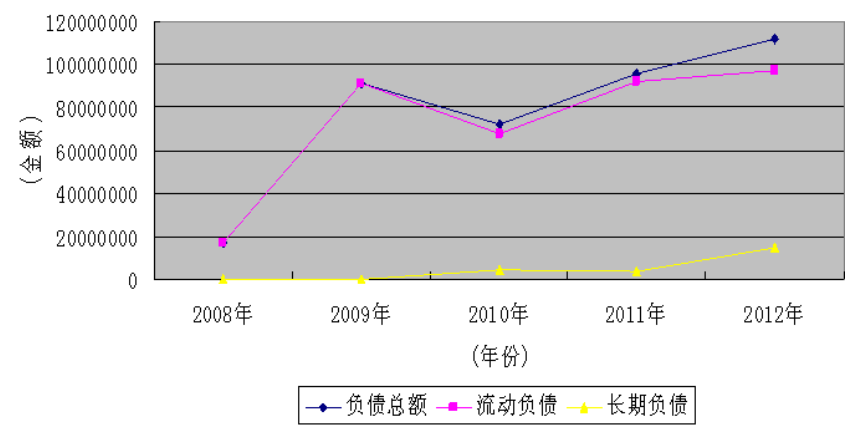

图 2 云意电气公司负债比较情况

根据上述分析, 公司应该充分发挥企业内部优势和外 部机会, 形成优势与机会相结合的战略, 研发、生产和销 售汽车电子产品, 充分利用强大的客户资源, 增加出口, 提 升售后空间。江苏云意电气股份有限公司是一个正在逐步 成长的企业, 因此, 财务战略的选择必须与企业的发展同 步。面对汽车制造业的不断发展, 江苏云意电气公司的发 展前景呈现一片良好的局势, 自企业 2012 年成功上市, 带 动净利润增长的同时, 也促使这一阶段的财务风险随之增 加, 现金的需求量也会有所增加, 所以, 成长型的企业在 实施财务战略的时候, 应充分考虑财务杜杆利益, 以弥补 资金的短缺。

在筹资战略方面。公司应该根据行业的发展经营和投 资理财规划、经营现金流入与经营及投资所需开支的差距, 有步骤的进行预期规划, 通过各方面努力, 提升企业信誉, 开拓融资渠道。另外, 将投资和融资二者配合使用, 充分 利用财务杜杆理论。由于公司目前现金需求量较大, 可以 采取适当的债权融资租赁, 而一些长期投资支出主要依靠 股权融资的方式去配合, 这样才能避免不必要的财务风险。

在投资战略方面。进一步加大相关项目的投资力度, 公司 2012 年研发产品共投入金额将近 2000 万元, 在公司 营业收入方面占据一定比重, 说明这一阶段公司认识到了 对企业核心的产品持续加大研发投资力度的重要性, 另外, 尝试多元化投资, 通过技术差异化战略的实施, 在分散风 险的同时, 适当增加公司运作厂房的数量, 进一步加强对 于海外市场的拓展力度, 争取使得公司主营产品在全国各 地甚至其他国家能够进行批量供货, 实现公司海外市场的 销售增长。

在营运战略方面。现阶段, 车用整流器和调节器市场
需求的十分巨大, 加之由于车辆制造厂家的零部件供应商 强烈关注产品质量, 因此, 公司与供应厂商建立长期的合 作关系对完善售后服务市场的而言是一项非常重要的内 容, 应着重注意产品的质量控制。持有尽可能低的现金节 约营运资金成本。

在利润分配战略方面。由于公司的现金流量并不稳定, 因此, 公司应该较少的采用现金股利分配政策, 尽可能的 使用留存收益来降低企业经营发展过程中的财务风险和资 本成本，这样能够节省现金流量以获得企业正常经营所需 要的资金。

\section{6. 结束语}

本文从理论上系统的研究了在特殊的行业背景下中小 企业财务战略的实施, 分析中小企业的特点及存在的相关 财务战略问题, 以江苏云意电气股份有限公司为载体, 对 企业的财务战略面临的问题和挑战进行了阐述, 并从筹资 战略、投资战略等方面进行了深入分析, 提出了有针对性 的建议。

\section{7. 致谢}

国家自然科学基金（71302188)、江苏省高校哲学社会 科学基金（2013SJB6300032）和江苏省“青蓝工程”资助。

\section{参考文献(References)}

[1] Myers, S. C. and Majluf, N.S. 'Corporate Financing and Investment Decisions when Firms have Information that Investors do not have', Journal of Financial Economics 13(1984), 187-221.

[2] Pandya and Rao,.M. Pandya, N.V. RaoDiversification and firm performance: an empirical evaluation. Journal of Financial and Strategic Decisions, 11 (2) (1998), pp. 67-81.

[3] Lee and Jang, M.J. Lee, S. Jang. Market diversification and financial performance and stability: a study of hotel companies. International Journal of Hospitality Management, 26 (2) (2007), pp. 362-375

[4] Stulz, R.M. Stulz. Globalization, corporate finance and the cost of capital. Journal of Applied Corporate Finance, 12 (1999), pp. $8-25$

[5] C.S. Sann, J. Grundy, J. Maynard, A. Brooks, M. Boreland, D. Sarak et al..Financial sustainability planning for immunization services in Cambodia. Health Policy Plan, 21 (4) (2006), pp. 302-309. 